\title{
The regulation of optimal development density is
}

\author{
Tan Lee ${ }^{\text {a }}$, Jyh-Bang Jou ${ }^{\text {b,* }}$ \\ a Department of International Business, Yuan Ze University, Taiwan \\ ${ }^{\mathrm{b}}$ Graduate Institute of National Development, National Taiwan University, Taiwan
}

Received 28 April 2006

Available online 18 April 2007

\begin{abstract}
This article investigates how a policy-maker should choose a density ceiling and how the optimal policy is affected by the underlying demand and technology parameters. We assume that developed properties reduce open space, and thereby harm urban residents. However, landowners will ignore this negative externality, and will thus develop property more densely than is socially optimal. A regulator can correct this by imposing a density ceiling control. The regulator should force developers to develop less densely when (1) land development becomes less risky, (2) the development costs are expected to grow more rapidly, and (3) the rents of undeveloped land are lower. This is because under these three scenarios, a social planner will choose to develop vacant land sooner, and thereby develop it less densely.

(C) 2007 Elsevier Inc. All rights reserved.
\end{abstract}

JEL classification: D62; G31; L51

Keywords: Development density; Negative externality; Real options; Regulation

\footnotetext{
We are grateful to the editor (Henry O. Pollakowski) and two anonymous reviewers for their constructive suggestions on this manuscript. We also would like to thank seminar participants at the 2003 Annual Conference of the Association for Chinese Management Educators, the 51st Annual Conference of the Australian Agricultural and Resource Economics Society, and the National Central University for their helpful comments on earlier versions of this manuscript. Tan Lee acknowledges financial support from the National Science Council, Executive Yuan, R.O.C. (Grant No. NSC-90-2416-H-155-027), and Jyh-Bang Jou acknowledges financial support from the Social Research Policy Center, College of Social Sciences, National Taiwan University.

* Corresponding author. Fax: +886 223679684.

E-mail addresses: tanlee@saturn.yzu.edu.tw (T. Lee), jbjou@ntu.edu.tw (J.-B. Jou).
} 


\section{Introduction}

Regulators generally prefer development density restrictions over all other policies to curb urban growth. ${ }^{1}$ The existing literature (see, e.g., Cunningham, 2004; Turnbull, 1991 ) investigates how density restrictions affect expected development timing in certainty and in a risky environment. By contrast, this article derives what the policy-maker's choices should be in a risky environment, and discusses how the optimal policy is affected by the underlying demand and technology parameters.

This article considers a real estate industry that consists of homogeneous landowners and renters. While developed properties reduce open space, and thus generate a negative external effect on urban residents, ${ }^{2}$ no one cares who provide these properties. In order to characterize this aggregate consumption-production externality (Tresch, 2002), ${ }^{3}$ we assume that each renter will pay a lower rent if the industry develops property more densely. There are two sources of market inefficiencies in our model: market power and the externality from congestion. While a monopolist in the real estate market can internalize the externality, it cannot follow the exact choices of a social planner because it ignores the welfare of renters. As compared to a social planner, the monopolist will value rents for houses less, and will therefore delay development. However, at their respective development option exercise points, both the social planner and the monopolist have the same marginal value from developing properties, and thus both will develop vacant land at the same density.

When the real estate market is not monopolized, landowners will develop property at a higher density than would be socially optimal. Consequently, the regulator can impose a density ceiling control policy to correct the tendency of landowners to overdevelop. ${ }^{4}$ In response, landowners will develop vacant land earlier than planned. ${ }^{5}$ It is optimal for a social planner to develop vacant land sooner, and thereby develop it less densely when (1) land development becomes less risky, (2) the development costs are expected to grow more rapidly, and (3) the rents of undeveloped land are lower. As a result, under these three scenarios the regulator should implement a more stringent density ceiling control policy.

The remainder of this article is organized as follows. Section 2 presents the basic model. Section 3 solves choices regarding the timing and density of development for both the decentralized and the centralized economy. Section 4 presents the comparative-statics results that show how various exogenous forces affect the optimal density control policy

\footnotetext{
${ }^{1}$ Based on a survey of 191 US jurisdictions in 1991, Pivo (1992, p. 4) finds that among 31 separate policies that are used to control urban growth, density ceiling regulation is the most popular, with $89 \%$ of the cities in the sample adopting it.

2 While Anderson (1993) has set a theoretic model that captures the externality from congestion, he focuses on the use of Pigouvian taxes rather than density ceiling control.

${ }^{3}$ Laffont (1988, pp. 193-200) provides an example regarding the relationship between the consumptionproduction externality and optimal taxation.

${ }^{4}$ Some articles also point out that externalities are one main reason for implementing zoning regulations. See, e.g., Fischel (1985).

5 See also a recent survey by Turnbull (2005) who points out that the literature on land use restrictions recognizes that the market response to land use regulation as actually implemented may differ considerately from the ultimate policy goal.
} 
chosen by the regulator and the timing of development chosen by landowners. Section 5 concludes and offers directions for further study.

\section{The model}

Consider a real estate industry that is composed of $N$ identical risk-neutral landowners. Suppose that at date $t=0$, this industry has undeveloped land that is normalized at one unit. At any time $t \geqslant 0$, landowner $i(i=1, \ldots, N)$ is able to develop property on a scale equal to $q_{i}$, and thus at a density equal to $N q_{i}$, given that each landowner has $1 / N$ units of undeveloped land. We also assume that the development cost for landowner $i$, which is fully irreversible, is equal to (see Quigg, 1993; Williams, 1991) ${ }^{6}$

$$
C\left(x_{1}(t), q_{i}\right)=x_{1}(t) q_{i}^{\eta}, \quad \eta>0,
$$

where $x_{1}(t)$ is a disturbance term that captures supply shocks such as unexpected changes in weather or labor market conditions. We allow the housing production technology to have either increasing $(\eta<1)$, constant $(\eta=1)$, or decreasing $(\eta>1)$ returns to scale.

We assume that the rent per unit of developed property is given by

$$
R(t)=x_{2}(t) Q^{b-1} S^{-a}, \quad 1 \geqslant b>a>0
$$

where $x_{2}(t)$ denotes the macroeconomic shock from the demand side, $Q$ is the aggregate demand for developed property, and $S=\sum_{i=1}^{N} q_{i}$ is the aggregate supply of developed property, which is also equal to the average density of development, given that the industry initially has one unit of undeveloped land. In Eq. (2), we assume that the rent of developed property is affected by two different measures of the scale of developed property. First, we assume a non-positive (internal) effect of $Q$ on $R(t)$ with a size measured by $b-1$. Given that $1 \geqslant b$, it indicates that the rent per unit of developed property is nonincreasing with the scale of developed property. Second, we assume a negative external effect of $S$ on $R(t)$ with a size measured by coefficient $a$; we call this effect external because the utility of a renter will be lower as the aggregate supply of developed property is higher. ${ }^{7}$ However, no individual renters can have an appreciable effect on $S$, and therefore, all renters will take the external effect as exogenously given when deciding whether to rent developed property. The rent function as specified in Eq. (2) is more generalized than that of Capozza and Li (1994) and Williams (1991), who not only assume that rents are unaffected by the aggregate demand for developed property (i.e., $b=1$ ), but also abstract from the consumption-production externalities (i.e., $a=0){ }^{8}$

Both the supply shock, $x_{1}(t)$, and the demand shock, $x_{2}(t)$, follow geometric Brownian motions given by

$$
\mathrm{d} x_{i}(t)=\alpha_{i} x_{i}(t) \mathrm{d} t+\sigma_{i} x_{i}(t) \mathrm{d} \Omega_{i}(t)
$$

\footnotetext{
${ }^{6}$ McFarlane (1999) argues that investment on land development will be fully irreversible if demolition costs are extremely high. Similarly, Riddiough (1997) suggests that irreversibility is a reasonable assumption for real estate in which the physical asset is long-lived and switching costs to alternative uses are quite high. Turnbull (2005) argues that the irreversibility assumption may not be realistic, but provides analytically tractable solutions.

7 The detailed proof is available upon request.

${ }^{8}$ Childs et al. (1996) and Grenadier (1996) also abstract from the consumption-production externalities.
} 
where $i=1$ or 2 . Each variable $x_{i}(t)$ has a constant expected rate of growth $\alpha_{i}$ and a constant variance of the growth rate $\sigma_{i}^{2}$. Each $\mathrm{d} \Omega_{i}(t)$ is an increment to a standard Wiener process, with $E\left\{\mathrm{~d} \Omega_{i}(t)\right\}=0, E\left\{\mathrm{~d} \Omega_{i}(t)\right\}^{2}=\mathrm{d} t$, and $E\left(\mathrm{~d} \Omega_{1}(t) \mathrm{d} \Omega_{2}(t)\right)=r_{12} \sigma_{1} \sigma_{2} \mathrm{~d} t$, where $-1 \leqslant r_{12} \leqslant 1$.

When property development exhibits negative externalities as shown in Eq. (2), the market outcome will be inefficient. The policies adopted to correct this include development density restrictions, and price controls such as property taxes, building fees, and entitlement fees. We abstract from these price control instruments, and instead focus only on density ceiling control. By following the literature that applies non-cooperative dynamic games to environmental management (see, e.g., Jou, 2001, 2004), we model density ceiling control as a hierarchical game. At the lower level of the game, landowners compete for the choices regarding the date and the scale of land development in a Cournot-Nash environment. At the upper level is a Stackelberg game in which the regulator acts as the leader and a landowner acts as the follower. The regulator should anticipate the scale chosen by the landowner, and then set the density ceiling at the socially optimal level accordingly.

We assume that the riskless rate of interest $\rho$ is constant per unit of time and that the undeveloped property per unit has a constant positive return given by net cash inflow per unit of time $\gamma x_{2}(t)$. We further assume that $\gamma>0$, an assumption implying that a landowner has no option value for abandoning the undeveloped property. We also abstract from both the time-to-build problem that usually occurs in the real estate industry (see, e.g., Bar-Ilan and Strange, 1996; Grenadier, 2000), and the redevelopment problem addressed in Williams (1997). Consequently, in what follows, each landowner as well as the social planner will make his respective development decisions once and for all.

\section{Choices of the date and the density of development}

Without risk of confusion, we use $x_{1}(t)=x_{1}$ and $x_{2}(t)=x_{2}$ in what follows. Consider any instant $\tau$ after vacant land is developed. Given that redevelopment is prohibited, the value of developed property is equal to the time $t$ expected present value of the future cash flow given by ${ }^{9}$

$$
W_{\mathrm{a}}\left(x_{2}, Q, q_{i}\right)=E_{t} \int_{t}^{\infty} \mathrm{e}^{-\rho(\tau-t)} q_{i} R(\tau) \mathrm{d} \tau=\frac{q_{i}}{\left(\rho-\alpha_{2}\right)} x_{2} Q^{b-1} S^{-a},
$$

where $q_{i} R(\tau)$ is the cash inflow for landowner $i$ at instant $\tau$, which is the product of the rent per unit of developed property, $R(\tau)$ in Eq. (2), and the scale of developed property he owns, $q_{i}$.

Define the value of vacant land from time $t$ to any future time $T$ as $W_{\mathrm{b}}\left(x_{2}, T\right)$, where $T$ denotes the date at which vacant land is developed. For later usage, we will calculate the value of vacant land if undeveloped forever (i.e., $T$ approaches infinity), which is equal to the time $t$ expected present value of the future flow given by

$$
W_{\mathrm{b}}\left(x_{2}, \infty\right)=E_{t} \int_{t}^{\infty} \mathrm{e}^{-\rho(\tau-t)} \frac{\gamma x_{2}(\tau)}{N} \mathrm{~d} \tau=\frac{\gamma x_{2}}{N\left(\rho-\alpha_{2}\right)} .
$$

We will investigate how to design optimal density controls by analyzing both the decentralized and the centralized economy. There are two sources of market inefficiencies in

\footnotetext{
${ }^{9}$ Here and in what follows, we assume that $\rho>\alpha_{2}$ so as to ensure that $W_{\mathrm{a}}(\cdot)$ given by Eq. (4) and $W_{\mathrm{b}}(\cdot)$ given by Eq. (5) are both finite. We also use subscripts "a" and "b" to represent "after" and "before" development in a decentralized economy, respectively.
} 
our model: market power and the externality from congestion. Consequently, both a landowner and the social planner will have different choices regarding the timing and the density of development.

\subsection{The decentralized economy}

First consider the case in which the economy is decentralized. Landowner $i$ needs to choose an appropriate date $T$ and density $q_{i}$ to maximize the expected value of the vacant land. This is defined as

$$
V_{\mathrm{d}}\left(x_{1}, x_{2}\right)=\max _{T, q_{i}} E_{t}\left\{\int_{t}^{T} \mathrm{e}^{-\rho(\tau-t)} \frac{\gamma x_{2}(\tau)}{N} \mathrm{~d} \tau+\int_{T}^{\infty} \mathrm{e}^{-\rho(\tau-t)} q_{i} x_{2}(\tau) Q^{b-1} S^{-a} \mathrm{~d} \tau-\mathrm{e}^{-\rho(T-t)} x_{1}(T) q_{i}^{\eta}\right\},
$$

subject to the evolution of $x_{1}(t)$ and $x_{2}(t)$ defined in Eq. (3). ${ }^{10}$ Eq. (6) indicates that the expected present value of returns to the vacant land is the sum of the expected present value of rents received until time $T$, the expected present value of land rent beginning at the time of development, less the expected present value of the developing costs. Following Capozza and Li (1994), Eq. (6) can be rewritten as

$$
V_{\mathrm{d}}\left(x_{1}, x_{2}\right)=W_{\mathrm{b}}\left(x_{2}, \infty\right)+Z_{\mathrm{d}}\left(x_{1}, x_{2}\right),
$$

where

$$
Z_{\mathrm{d}}\left(x_{1}, x_{2}\right)=\max _{T, q_{i}} E_{t}\left\{\mathrm{e}^{-\rho(T-t)}\left[\int_{T}^{\infty} \mathrm{e}^{-\rho(\tau-T)}\left(q_{i} x_{2}(\tau) Q^{b-1} S^{-a}-\frac{\gamma x_{2}(\tau)}{N}\right) \mathrm{d} \tau-x_{1}(T) q_{i}^{\eta}\right]\right\} .
$$

In Eq. (8), $Z_{\mathrm{d}}\left(x_{1}, x_{2}\right)$ is the net value of a perpetual warrant to exchange the fixed $q_{i}$ units of developed properties for $1 / N$ units of vacant land.

Define $W_{\mathrm{d}}\left(x_{1}, x_{2}\right)$ as the intrinsic value of the warrant if exercised at time $t$. Substituting $T=t$ into Eq. (8) yields its value as given by

$$
W_{\mathrm{d}}\left(x_{1}, x_{2}\right)=\max _{q_{i}}\left\{W_{\mathrm{a}}\left(x_{2}, Q, q_{i}\right)-W_{\mathrm{b}}\left(x_{2}, \infty\right)-x_{1} q_{i}^{\eta}\right\},
$$

where the term in braces are the value of developed properties, $W_{\mathrm{a}}\left(x_{2}, Q, q_{i}\right)$, minus the opportunity costs of obtaining it, namely, the value of vacant land if undeveloped forever, $W_{\mathrm{b}}\left(x_{2}, \infty\right)$, and the costs of development, $x_{1} q_{i}^{\eta}$. To maximize the intrinsic value at time $t$, the optimal scale of development, denoted by $q_{\mathrm{d}}$, must satisfy the first-order condition for $q_{i}$ :

$$
\frac{\partial\left\{W_{\mathrm{a}}\left(x_{2}, Q, q_{i}\right)-x_{1} q_{i}^{\eta}\right\}}{\partial q_{i}}=0
$$

which says that at the optimal scale of development, the expected marginal benefit of an additional scale of development must be equal to the marginal cost of developing it. Given that the intrinsic value of the warrant, if exercised at the optimal exercise date $T$, may be denoted by $W_{\mathrm{d}}\left(x_{1}(T), x_{2}(T)\right)$, we can rewrite Eq. (8) as

$$
Z_{\mathrm{d}}\left(x_{1}, x_{2}\right)=\max _{T} E_{t}\left\{\mathrm{e}^{-\rho(T-t)} W_{\mathrm{d}}\left(x_{1}(T), x_{2}(T)\right)\right\} .
$$

\footnotetext{
${ }^{10}$ Here and in what follows, we use subscript "d" to represent "the decentralized economy."
} 
The solution for $Z_{\mathrm{d}}\left(x_{1}, x_{2}\right)$ must satisfy the fundamental differential equation of optimal stopping given by

$$
\begin{aligned}
& \frac{1}{2} \sigma_{1}^{2} x_{1}^{2} \frac{\partial^{2} Z_{\mathrm{d}}(\cdot)}{\partial x_{1}^{2}}+r_{12} \sigma_{1} \sigma_{2} x_{1} x_{2} \frac{\partial^{2} Z_{\mathrm{d}}(\cdot)}{\partial x_{1} \partial x_{2}}+\frac{1}{2} \sigma_{2}^{2} x_{2}^{2} \frac{\partial^{2} Z_{\mathrm{d}}(\cdot)}{\partial x_{2}^{2}} \\
& +\alpha_{1} x_{1} \frac{\partial Z_{\mathrm{d}}(\cdot)}{\partial x_{1}}+\alpha_{2} x_{2} \frac{\partial Z_{\mathrm{d}}(\cdot)}{\partial x_{2}}-\rho Z_{\mathrm{d}}(\cdot)=0 .
\end{aligned}
$$

The solution to Eq. (12) is given by

$$
Z_{\mathrm{d}}\left(x_{1}, x_{2}\right)=A_{1 \mathrm{~d}} x_{2}^{\beta_{1}} x_{1}^{1-\beta_{1}}+A_{2 \mathrm{~d}} x_{2}^{\beta_{2}} x_{1}^{1-\beta_{2}},
$$

where $A_{1 \mathrm{~d}}$ and $A_{2 \mathrm{~d}}$ are constants to be determined, and $\beta_{1}, \beta_{2}$, and the overall volatility, denoted by $\sigma^{2}$, are respectively equal to

$$
\begin{aligned}
& \beta_{1}=\frac{1}{2}-\frac{\left(\alpha_{2}-\alpha_{1}\right)}{\sigma^{2}}+\sqrt{\left(\frac{1}{2}-\frac{\left(\alpha_{2}-\alpha_{1}\right)}{\sigma^{2}}\right)^{2}+\frac{2\left(\rho-\alpha_{1}\right)}{\sigma^{2}}}, \\
& \beta_{2}=\frac{1}{2}-\frac{\left(\alpha_{2}-\alpha_{1}\right)}{\sigma^{2}}-\sqrt{\left(\frac{1}{2}-\frac{\left(\alpha_{2}-\alpha_{1}\right)}{\sigma^{2}}\right)^{2}+\frac{2\left(\rho-\alpha_{1}\right)}{\sigma^{2}}} \\
& \sigma^{2}=\sigma_{1}^{2}-2 r_{12} \sigma_{1} \sigma_{2}+\sigma_{2}^{2} .
\end{aligned}
$$

Landowner $i$ simultaneously chooses the timing and the scale of development. As indicated by Dixit and Pindyck (1994, p. 139), when uncertainty arises, we are unable to determine a non-stochastic timing. Instead, the development rule takes the form where landowner $i$ will not develop until the supply shock, $x_{1}$, declines to a certain level, denoted by $x_{1 \mathrm{~d}}$, and the demand-shift factor, $x_{2}$, rises to another level, denoted by $x_{2 \mathrm{~d}}$. When these two trigger levels are reached, landowner $i$ will develop vacant land at a scale denoted by $q_{\mathrm{d}}$. The two critical levels, $x_{1 \mathrm{~d}}$ and $x_{2 \mathrm{~d}}$, together with $A_{1 \mathrm{~d}}$ and $A_{2 \mathrm{~d}}$ in Eq. (13), are solved from the boundary conditions given by

$$
\begin{aligned}
& \lim _{x_{2} \rightarrow 0} Z_{\mathrm{d}}\left(x_{1}, x_{2}\right)=0, \\
& Z_{\mathrm{d}}\left(x_{1 \mathrm{~d}}, x_{2 \mathrm{~d}}\right)=W_{\mathrm{d}}\left(x_{1 \mathrm{~d}}, x_{2 \mathrm{~d}}\right), \\
& \frac{\partial Z_{\mathrm{d}}\left(x_{1 \mathrm{~d}}, x_{2 \mathrm{~d}}\right)}{\partial x_{1}}=\frac{\partial W_{\mathrm{d}}\left(x_{1 \mathrm{~d}}, x_{2 \mathrm{~d}}\right)}{\partial x_{1}}, \\
& \frac{\partial Z_{\mathrm{d}}\left(x_{1 \mathrm{~d}}, x_{2 \mathrm{~d}}\right)}{\partial x_{2}}=\frac{\partial W_{\mathrm{d}}\left(x_{1 \mathrm{~d}}, x_{2 \mathrm{~d}}\right)}{\partial x_{2}} .
\end{aligned}
$$

Eq. (15) is the limit condition, which states that the option value of vacant land is worthless as the demand-shift factor approaches zero. Eq. (16) is the value-matching condition which states that at the optimal timing of development, landowner $i$ should be indifferent as to whether vacant land is developed or not. Eqs. (17) and (18) are the smooth-pasting conditions, which require that landowner $i$ not obtain any arbitrage profits from deviating from the optimal timing of development.

Eqs. (15)-(18) are satisfied by the value function $Z_{\mathrm{d}}(\cdot)$ that is linearly homogeneous in $x_{1}$ and $x_{2}$, and thus we can define $y=x_{2} / x_{1}, z_{\mathrm{d}}(y)=Z_{\mathrm{d}}\left(x_{1}, x_{2}\right) / x_{1}, w_{\mathrm{a}}\left(y, Q, q_{i}\right)=$ $W_{\mathrm{a}}\left(x_{2}, Q, q_{i}\right) / x_{1}$, and $w_{\mathrm{d}}(y)=W_{\mathrm{d}}\left(x_{1}, x_{2}\right) / x_{1}$ (see Williams, 1991). Note that a higher value of $y$ indicates that the state of nature is better because it comes from a larger value of $x_{2}$ 
and/or a smaller value of $x_{1}$, i.e., when demand for developed property is increased and/or the cost of developing land is reduced. Eq. (4) can then be rewritten as

$$
w_{\mathrm{a}}\left(y, Q, q_{i}\right)=\frac{q_{i} y Q^{b-1} S^{-a}}{\left(\rho-\alpha_{2}\right)},
$$

while Eqs. (15)-(18) can be rewritten as

$$
\begin{aligned}
& \lim _{y \rightarrow 0} z_{\mathrm{d}}(y)=0, \\
& z_{\mathrm{d}}\left(y_{\mathrm{d}}\right)=w_{\mathrm{d}}\left(y_{\mathrm{d}}\right), \\
& \frac{\partial z_{\mathrm{d}}\left(y_{\mathrm{d}}\right)}{\partial y}=\frac{\partial w_{\mathrm{d}}\left(y_{\mathrm{d}}\right)}{\partial y},
\end{aligned}
$$

where $y_{\mathrm{d}}\left(=x_{2 \mathrm{~d}} / x_{1 \mathrm{~d}}\right)$ is the development timing chosen by landowner $i$. Define $Q_{\mathrm{d}}$ as the aggregate scale (density) of development chosen by all landowners as a whole. In Cournot-Nash equilibrium, all landowners will choose the same scale of development such that $Q=S=N q_{\mathrm{d}}=Q_{\mathrm{d}}$. To solve a landowner's choice of development timing, we can first solve $A_{1 \mathrm{~d}}$ and $A_{2 \mathrm{~d}}$ from Eqs. (20) and (22), respectively. We can then substitute these values and impose the Cournot-Nash equilibrium condition on Eq. (21). Referring to the result as $T_{\mathrm{d}}^{*}\left(y_{\mathrm{d}}, Q_{\mathrm{d}}\right)$ yields

$$
T_{\mathrm{d}}^{*}\left(y_{\mathrm{d}}, Q_{\mathrm{d}}\right)=-\left(1-\frac{1}{\beta_{1}}\right) \frac{y_{\mathrm{d}}}{N} \frac{\left(Q^{b-a}-\gamma\right)}{\left(\rho-\alpha_{2}\right)}+\left(\frac{Q_{\mathrm{d}}}{N}\right)^{\eta}=0 .
$$

On the other hand, dividing Eq. (10) by $x_{1}$ yields

$$
\frac{\partial\left\{w_{\mathrm{a}}\left(y, Q, q_{i}\right)-q_{i}^{\eta}\right\}}{\partial q_{i}}=0 .
$$

Imposing $y=y_{\mathrm{d}}$ and the Cournot-Nash equilibrium condition on Eq. (24), and referring its result as $D_{\mathrm{d}}^{*}\left(y_{\mathrm{d}}, Q_{\mathrm{d}}\right)$ yields

$$
D_{\mathrm{d}}^{*}\left(y_{\mathrm{d}}, Q_{\mathrm{d}}\right)=\frac{(N-1+b-a)}{N\left(\rho-\alpha_{2}\right)} y_{\mathrm{d}} Q_{\mathrm{d}}^{b-a-1}-\eta\left(\frac{Q_{\mathrm{d}}}{N}\right)^{\eta-1}=0 .
$$

Solving Eqs. (23) and (25) simultaneously yields

$$
\begin{aligned}
y_{\mathrm{d}} & =\frac{\eta\left(\rho-\alpha_{2}\right)}{(N-1+b-a) N^{(\eta-2)}} M_{\mathrm{d}}^{(\eta /(b-a))-1}, \\
Q_{\mathrm{d}} & =M_{\mathrm{d}}^{1 /(b-a)},
\end{aligned}
$$

where

$$
M_{\mathrm{d}}=\gamma\left[1-\frac{(N-1+b-a)}{\eta N}\left(1-\frac{1}{\beta}\right)^{-1}\right]^{-1} \cdot{ }^{11}
$$

We have obtained analytically tractable solutions for both the choice of date, $y_{\mathrm{d}}$, and choice of density, $Q_{\mathrm{d}}$. However, to gain more insights regarding how the underlying exog-

\footnotetext{
${ }^{11}$ It is required that terms inside the brackets on the right-hand side of Eq. (28) be positive. We adopt this requirement here and in what follows, which is more likely to hold if a, $\eta, \alpha_{1}$, and $\rho$ are larger or $\mathrm{N}, \sigma$, and $\alpha_{2}$ are smaller.
} 
enous forces affect $y_{\mathrm{d}}$ and $Q_{\mathrm{d}}$, we will focus on both the condition for deriving $y_{\mathrm{d}}$ given by Eq. (23), and for deriving $Q_{\mathrm{d}}$ given by Eq. (25). Eq. (23) implicitly defines the positive dependence of $y_{\mathrm{d}}$ on $Q_{\mathrm{d}}$, and Eq. (25) implicitly defines the positive dependence of $Q_{\mathrm{d}}$ on $y_{\mathrm{d}}$. We derive these two relationships in Eqs. (A1)-(A7) in Appendix A.

We assume that landowners compete in a Cournot-Nash environment. Alternatively, we may assume that landowners compete in a Stackelberg environment. If two landowners compete in this environment, then three equilibria may arise. ${ }^{12}$ One of these three is exactly the same as the one that we obtain in the Cournot-Nash environment. We focus on this one because it is the only one for which we are able to obtain analytically tractable solutions.

\subsection{The centralized economy}

Consider the case of the centralized economy. A social planner will internalize the negative externality before choosing the development timing and density. We can thus impose $N q_{i}=S=Q$ on Eqs. (1) and (5), and then multiply the results by $N$, thus yielding the social development cost function, and the social value of vacant land if undeveloped forever, respectively: ${ }^{13}$

$$
\begin{aligned}
& C_{\mathrm{A}}\left(x_{1}, Q\right)=N x_{1}\left(\frac{Q}{N}\right)^{\eta}, \\
& W_{\mathrm{B}}\left(x_{2}, \infty\right)=\frac{\gamma x_{2}}{\left(\rho-\alpha_{2}\right)} .
\end{aligned}
$$

The social rent function is given by imposing $Q=S$ on Eq. (2), thus yielding

$$
R_{\mathrm{A}}=x_{2} Q^{b-a-1} \text {. }
$$

Given the social rent function in Eq. $\left(2^{\prime}\right)$, the total social surplus is equal to the area under the demand curve shown by Eq. $\left(2^{\prime}\right)$, that is,

$$
R_{\mathrm{A}}^{\prime}\left(x_{2}, Q\right)=\int_{0}^{Q} x_{2}(\tau) q^{b-a-1} \mathrm{~d} q=\frac{x_{2} Q^{b-a}}{(b-a)}
$$

Consider any instant $\tau$ after development. The social value of developed property is equal to the time $t$ expected present value of the total social surplus given by

$$
W_{\mathrm{A}}\left(x_{2}, Q\right)=E_{t} \int_{t}^{\infty} \mathrm{e}^{-\rho(\tau-t)} \frac{x_{2}(\tau) Q^{b-a}}{(b-a)} \mathrm{d} \tau=\frac{x_{2} Q^{b-a}}{\left(\rho-\alpha_{2}\right)(b-a)} .
$$

The social planner will choose an appropriate date and scale to maximize the expected present discounted value of social welfare. This is defined as

$$
V_{\mathrm{c}}\left(x_{1}, x_{2}\right)=W_{\mathrm{B}}\left(x_{2}, \infty\right)+Z_{\mathrm{c}}\left(x_{1}, x_{2}\right),
$$

where

$$
Z_{\mathrm{c}}\left(x_{1}, x_{2}\right)=\max _{T, Q} E_{t}\left\{\mathrm{e}^{-\rho(T-t)}\left[\int_{T}^{\infty} x_{2}(\tau)\left(\frac{Q^{b-a}}{(b-a)}-\gamma\right) \mathrm{d} \tau-N x_{1}(T)\left(\frac{Q}{N}\right)^{\eta}\right]\right\} .
$$

\footnotetext{
12 We can follow Grenadier (1996) to prove this. The detailed proof is available upon request.

13 Here and in what follows, we use the subscript "c" to represent " the centralized economy," while subscript "A" and "B" represent "after" and "before" development in a centralized economy.
} 
In Eq. $\left(8^{\prime}\right), Z_{\mathrm{c}}\left(x_{1}, x_{2}\right)$ is the social value of a perpetual warrant to exchange the fixed $Q$ units of developed properties for one unit of vacant land.

Define $W_{\mathrm{c}}\left(x_{1}, x_{2}\right)$ as the intrinsic value of the warrant if exercised at time $t$, that is,

$$
W_{\mathrm{c}}\left(x_{1}, x_{2}\right)=\max _{Q}\left\{W_{\mathrm{A}}\left(x_{2}, Q\right)-W_{\mathrm{B}}\left(x_{2}, \infty\right)-C_{\mathrm{A}}\left(x_{1}, Q\right)\right\} .
$$

To maximize the intrinsic value at time $t$, the optimal scale, denoted by $Q_{\mathrm{c}}$, must satisfy the first-order condition for $Q$ :

$$
\frac{\partial\left\{W_{\mathrm{A}}\left(x_{2}, Q\right)-C_{\mathrm{A}}\left(x_{1}, Q\right)\right\}}{\partial Q}=0 .
$$

Given that the intrinsic value of the warrant, if exercised at the optimal exercise date $T$, may be devoted by $W_{\mathrm{c}}\left(x_{1}(T), x_{2}(T)\right)$, we can write Eq. $\left(8^{\prime}\right)$ as

$$
Z_{\mathrm{c}}\left(x_{1}, x_{2}\right)=\max _{T} E_{t}\left\{\mathrm{e}^{-\rho(T-t)} W_{\mathrm{c}}\left(x_{1}(T), x_{2}(T)\right)\right\} .
$$

Following similar arguments to those for the case of decentralized economy yields

$$
Z_{\mathrm{c}}\left(x_{1}, x_{2}\right)=A_{1 \mathrm{c}} x_{2}^{\beta_{1}} x_{1}^{1-\beta_{1}}+A_{2 \mathrm{c}} x_{2}^{\beta_{2}} x_{1}^{1-\beta_{2}},
$$

where $A_{1 \mathrm{c}}$ and $A_{2 \mathrm{c}}$ are constants to be determined. Define $y_{\mathrm{c}}\left(=x_{2 \mathrm{c}} / x_{1 \mathrm{c}}\right)$ as the timing to develop vacant land and $Q_{\mathrm{c}}$ as the density chosen by the social planner, respectively. Applying similar conditions as shown by Eqs. (20), (21), (22) and (24), and imposing the constraint $Q=Q_{\mathrm{c}}$ on those conditions yields the counterparts of Eqs. (23) and (25) as given by

$$
\begin{aligned}
& T_{\mathrm{c}}^{*}\left(y_{\mathrm{c}}, Q_{\mathrm{c}}\right)=-\left(1-\frac{1}{\beta_{1}}\right) \frac{y_{\mathrm{c}}}{\left(\rho-\alpha_{2}\right)(b-a)}\left[Q_{\mathrm{c}}^{b-a}-\gamma\right]+N\left(\frac{Q_{\mathrm{c}}}{N}\right)^{\eta}=0, \\
& D_{\mathrm{c}}^{*}\left(y_{\mathrm{c}}, Q_{\mathrm{c}}\right)=\frac{1}{\left(\rho-\alpha_{2}\right)} y_{\mathrm{c}} Q_{\mathrm{c}}^{b-a-1}-\eta\left(\frac{Q_{\mathrm{c}}}{N}\right)^{\eta-1}=0 .
\end{aligned}
$$

Solving Eqs. (29) and (30) simultaneously yields

$$
\begin{aligned}
& y_{\mathrm{c}}=\frac{\eta\left(\rho-\alpha_{2}\right)}{N^{(\eta-1)}} M_{\mathrm{c}}^{(\eta /(b-a))-1}, \\
& Q_{\mathrm{c}}=M_{\mathrm{c}}^{1 /(b-a)},
\end{aligned}
$$

where

$$
M_{\mathrm{c}}=\gamma\left[1-\frac{b-a}{\eta}\left(1-\frac{1}{\beta_{1}}\right)^{-1}\right]^{-1} .
$$

Eq. (29) implicitly defines the dependence of $y_{\mathrm{c}}$ on $Q_{\mathrm{c}}$, while Eq. (30) implicitly defines the dependence of $Q_{\mathrm{c}}$ on $y_{\mathrm{c}}$. We derive these two relationships in Eqs. (B1)-(B7) in Appendix B.

\section{Comparative-statics results}

Comparing Eqs. (26)-(31), and (27)-(32) yields the result stated in Proposition 1 below. 
Proposition 1. As compared to asocial planner, (a) a sole owner of all vacant land will develop property later, but at the same density; $(b)$ a landowner will develop property later but more densely if the real estate market is not monopolized.

Proof. If $N=1, M_{\mathrm{d}}=M_{\mathrm{c}}$ such that $Q_{\mathrm{d}}=Q_{\mathrm{c}}$ and $y_{\mathrm{d}}>y_{\mathrm{c}}$. If $N>1, M_{\mathrm{d}}>M_{\mathrm{c}}$ such that $Q_{\mathrm{d}}>Q_{\mathrm{c}}$ and $y_{\mathrm{d}}>y_{\mathrm{c}}$.

We explain the intuition behind Proposition 1(a) as follows. Both a sole owner of all vacant land and a social planner can internalize the external effect of congestion. However, the sole landowner cares about the welfare of himself only, while the social planner cares about the social welfare in the form of consumer surplus and development resource supplier's surplus. The value of developed property is thus higher from the viewpoint of the social planner than from the sole landowner. As a result, the social planner will exercise the development option earlier than the sole landowner. At their respective development option exercise points, however, the marginal values of developed property for both are exactly the same. Consequently, both will choose the same scale of development.

We use Fig. 1 to explain the intuition behind Proposition 1(b), where the real estate market is not monopolized. The lines $T_{\mathrm{d}} T_{\mathrm{d}}$ and $T_{\mathrm{c}} T_{\mathrm{c}}$ depict the dependence of the choice of the date on the density of development defined in Eqs. (23) and (29), respectively. On the other hand, the lines $D_{\mathrm{d}} D_{\mathrm{d}}$ and $D_{\mathrm{c}} D_{\mathrm{c}}$ depict the dependence of the choice of the density on the date of development defined in Eqs. (25) and (30), respectively.

Fig. 1 shows that the line $T_{\mathrm{c}} T_{\mathrm{c}}$ lies below the line $T_{\mathrm{d}} T_{\mathrm{d}}$, indicating that when the density of development is fixed, a social planner will exercise the development option earlier than a landowner. Fig. 1 also shows that the line $D_{\mathrm{c}} D_{\mathrm{c}}$ lies to the right of the line $D_{\mathrm{d}} D_{\mathrm{d}}$. This indicates that when the timing of development is fixed, the social planner will develop property more densely than the landowner because the social marginal value from developing vacant land will be larger than its private marginal value. Allowing for the interaction of choices of the development timing and density, however, Fig. 1 indicates that the social planner will develop earlier but less densely than the landowner. This is shown by point A, which denotes the equilibrium for the centralized economy at the intersection of lines $T_{\mathrm{c}} T_{\mathrm{c}}$ and $D_{\mathrm{c}} D_{\mathrm{c}}$, for which the optimal density is $Q_{\mathrm{c}}$ and the optimal date of development is $y_{\mathrm{c}}$.

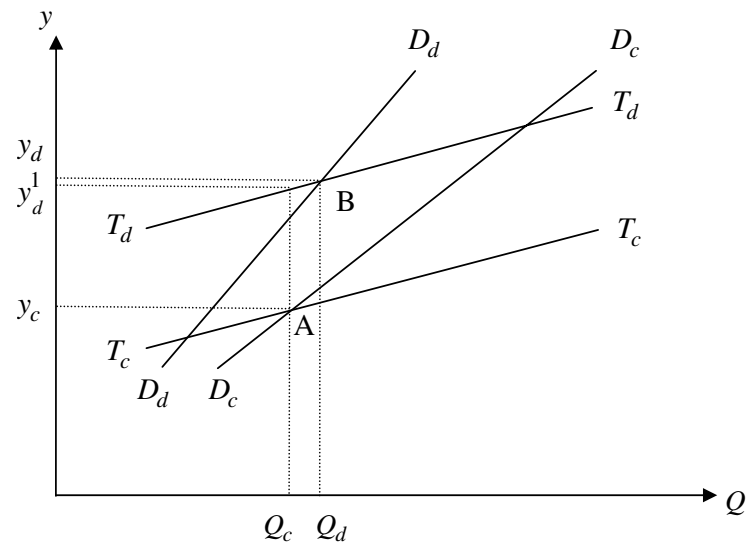

Fig. 1. Difference between the centralized and the decentralized economy when the real estate is not monopolized. 
By contrast, point $\mathrm{B}$ denotes the equilibrium for a landowner in the decentralized economy, at the intersection of lines $T_{\mathrm{d}} T_{\mathrm{d}}$ and $D_{\mathrm{d}} D_{\mathrm{d}}$, for which the optimal density is $Q_{\mathrm{d}}$ and the optimal date of development is $y_{\mathrm{d}}$. Proposition 1(b) then follows because $Q_{\mathrm{d}}>Q_{\mathrm{c}}$ and $y_{\mathrm{d}}>y_{\mathrm{c}}$.

Proposition 1(b) indicates that a landowner will develop more densely than the socially optimal level when the real estate market is not monopolized. Therefore, a social planner can impose a density control policy to correct this inefficient outcome. We now explain the way to design this policy, and how a landowner responds to it by using Fig. 1. As mentioned in Section 2, our model presents a hierarchical game. At the lower level, a landowner competes with the other landowners in a Cournot-Nash environment, and chooses both a density level equal to $Q_{\mathrm{d}}$ and a date of development equal to $y_{\mathrm{d}}$. At the upper level, the regulator acts as the leader and the landowner acts as the follower. The regulator, who anticipates that the density chosen by the landowner will be above the socially optimal level, $Q_{\mathrm{c}}$, will thus set the density at this optimal level. Under this regulation, a landowner will be forced to develop property at the date given by $y_{\mathrm{d}}^{1}$, which is later than the date of development chosen by the regulator, $y_{\mathrm{c}}$, but is earlier than that chosen by the landowner in the absence of any regulation, $y_{\mathrm{d}}$. The fact that $y_{\mathrm{d}}^{1}<y_{\mathrm{d}}$ implies the following proposition:

Proposition 2. When the real estate market is not monopolized, a landowner will develop earlier in response to the density ceiling control policy.

The results of Proposition 2 are in line with the extant literature including Titman (1985), Turnbull (1991), and Cunningham (2004). ${ }^{14}$ First, Titman argues that the initiation of height restrictions may enhance development because of the consequent decrease in uncertainty regarding the optimal height of the buildings (see Titman, $p$. 506). Second, Turnbull employs a perfect foresight dynamic model to investigate the residential development process of an urban area, and classifies the area into three sites-A, B, and C. He then shows that binding density ceilings can exhibit different effects on the choice of the timing of development for these three sites. In particular, the effects stated in Proposition 2 resemble those for site C. Finally, Cunningham applies the model of Capozza and Li (1994), and suggests that the density ceiling regulation corresponds to the situation in which capital intensity is fixed. Cunningham then shows that, as compared to the case where capital intensity is allowed to be varied, the incentive for a landowner to develop will be higher when capital intensity is fixed. ${ }^{15}$

Most studies on density ceiling regulation focus on how landowners react to this policy. By contrast, we investigate the design of this policy by incorporating the production-consumption externality into the objective function of a regulator. Specifically, we discuss the upper level of the hierarchical game in which the regulator sets up different levels of density ceiling control in response to changes in the demand and

\footnotetext{
${ }_{14}$ Our result stated in Proposition 2 is just the opposite of the argument of Williams (1991). However, Williams has made a mistake in deriving the relationship between density ceiling regulation and the timing of property development. Jou and Lee (2007) show that in Williams's model, if the imposed density is decreased from its binding level, then a landowner may either develop later (as suggested by Williams) or develop earlier.

${ }^{15}$ See also Turnbull (2002), who provides a model to explain why a threat of the density ceiling regulation may hasten development.
} 


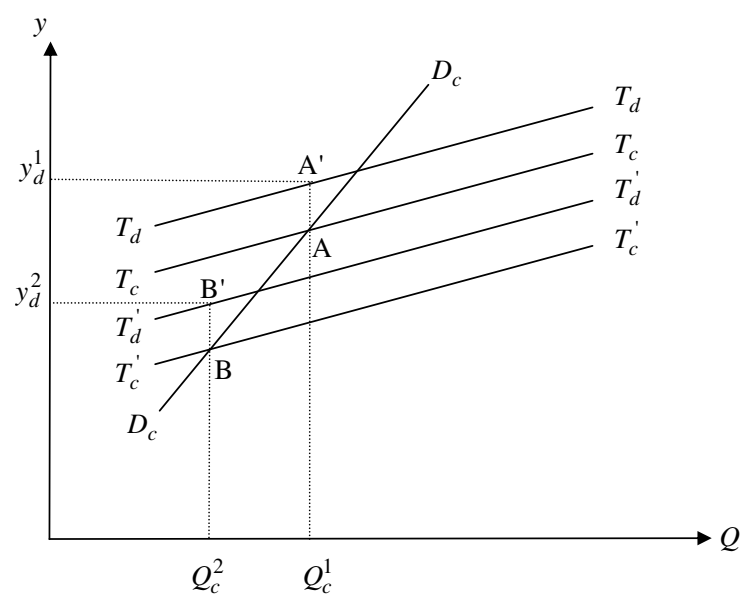

Fig. 2. A fall in $\sigma, \gamma$ or a rise in $\alpha_{1}$.

technology parameters. We also investigate how the regulator's response affects a landowner's choice of the date on which to develop. These results are stated in Proposition 3.

Proposition 3. Suppose that the real estate market is not monopolized. The regulator should then impose a more stringent density control policy such that a landowner will develop property earlier if $(i)$ the net return derived from land development becomes less volatile, i.e., $\sigma$ is decreased, (ii) the development costs are expected to grow more rapidly, i.e., $\alpha_{1}$ is increased, and (iii) the rents of undeveloped land are lower, i.e., $\gamma$ is decreased. ${ }^{16}$

\section{Proof. See Appendix C.}

We use Fig. 2 to explain the reason for Proposition 3 as follows. Suppose that the initial equilibrium for the centralized economy may be represented by point $A$, the intersection of lines $D_{\mathrm{c}} D_{\mathrm{c}}$ and $T_{\mathrm{c}} T_{\mathrm{c}}$. Consequently, a regulator should impose the density ceiling at $Q_{\mathrm{c}}^{1}$. An individual landowner will then be forced to develop vacant land at a date equal to $y_{\mathrm{d}}^{1}$ such that the combination of $\left(y_{\mathrm{d}}^{1}, Q_{\mathrm{c}}^{1}\right)$, i.e., point $\mathrm{A}^{\prime}$, satisfies the choice of the development timing for the decentralized economy characterized by the line $T_{\mathrm{d}} T_{\mathrm{d}}$. First, suppose that the overall volatility is decreased such that land development is less risky. ${ }^{17}$ A social planner would like to develop property sooner because it is less likely to gain huge profits from delaying development. Second, if the social plan-

\footnotetext{
${ }^{16}$ However, as the demand for developed property is expected to grow more slowly ( $\alpha_{2}$ is smaller), the regulator will set a more stringent density control, but a landowner may develop earlier, later, or according to the same schedule. Furthermore, a change in the external effect $(a)$ or the cost elasticity of scale $(\eta)$ will exhibit an ambiguous effect on both the optimal density regulation as well as the landowner's choice of timing of development. Finally, we find that an increase in $N$ will not affect the development density chosen by the social planner. We do not discuss this issue because an increase in $N$ not only indicates a more atomistic land ownership structure, but also changes the assumed technology for the industry as a whole. The proofs for all above results are omitted to save space.

${ }^{17}$ The overall volatility will be smaller if $r_{12}$ is higher, i.e., if more (less) advantageous supply conditions are associated with less (more) prospective demand conditions in the real estate market.
} 
ner expects the development costs to grow more rapidly ( $\alpha_{1}$ is larger), he had better develop property sooner to avoid the larger costs of development in the future. Finally, if the rents of undeveloped property $(\gamma)$ are lower, the social planner will not regret developing sooner because his opportunity costs from developing property become lower. These parameter changes that accelerate development are indicated by Eqs. (C1)-(C3), and are shown by the line $T_{\mathrm{c}} T_{\mathrm{c}}$, which shifts downward to line $T_{\mathrm{c}}^{\prime} T_{\mathrm{c}}^{\prime}$. Similarly, these parameter changes will also accelerate development for the decentralized economy, which is shown by the line $T_{\mathrm{d}} T_{\mathrm{d}}$, which shifts downward to line $T_{\mathrm{d}}^{\prime} T_{\mathrm{d}}^{\prime}$. Given that these parameter changes are unrelated to the condition for the choice of the development density (see Eq. (C4)), the new equilibrium for the centralized economy thus moves from point $\mathrm{A}$ to point $\mathrm{B}$, at which the social planner develops vacant land at a density equal to $Q_{\mathrm{c}}^{2}$. As a result, an individual landowner will be forced to develop at a date equal to $y_{\mathrm{d}}^{2}$ such that the combination of $\left(y_{\mathrm{d}}^{2}, Q_{\mathrm{c}}^{2}\right)$, i.e., point $\mathbf{B}^{\prime}$, satisfies the choice of the development timing for the decentralized economy characterized by the line $T_{\mathrm{d}}^{\prime} T_{\mathrm{d}}^{\prime}$. The statement in Proposition 3 will thus follow because these parameter changes not only induce the regulator to set a more stringent level of development density $Q_{\mathrm{c}}^{2}\left(<Q_{\mathrm{c}}^{1}\right)$, but also induce an individual landowner to develop property at an earlier date $y_{\mathrm{d}}^{2}\left(<y_{\mathrm{d}}^{1}\right)$.

\section{Conclusion}

This article investigates how a policy-maker should choose a density ceiling and how the optimal policy is affected by the underlying demand and technology parameters. Given that landowners will ignore the negative externality resulting from their property development decisions on urban residents, the regulator had better implement density ceiling controls. We show that the regulator should control density more stringently when (1) land development becomes less risky, (2) the development costs are expected to grow more rapidly, and (3) the rents of undeveloped land are lower.

Some caveats deserve mentioning here. This article constructs a simplified model, and thus abstracts from several key elements that are important in designing density ceiling regulation. One element is the spatial factor. This factor can be incorporated into the rent function in Eq. (2). For example, we can follow Turnbull (1988) by assuming that the longer the distance between a parcel of land and the central business district, the lower the rent derived from the developed property will be. As a result, the optimal level of density ceiling control will be a function of the spatial factor. However, the regulator may be unable to implement a policy that differentiates density ceiling control across different locations. Instead, he may be forced to implement a uniform density ceiling control policy. It will be interesting to investigate whether such a policy still accelerates development.

\section{Appendix A. Relationship between $y_{\mathrm{d}}$ and $Q_{\mathrm{d}}$}

Totally differentiating Eq. (23) with respect to $Q_{\mathrm{d}}$, and using Eqs. (26)-(28) yields

$$
\frac{\partial y_{\mathrm{d}}}{\partial Q_{\mathrm{d}}}=\frac{\Delta_{12}}{-\Delta_{11}}>0
$$

where 


$$
\begin{aligned}
& \Delta_{11}=\frac{\partial T_{\mathrm{d}}^{*}\left(y_{\mathrm{d}}, Q_{\mathrm{d}}\right)}{\partial y_{\mathrm{d}}}=-\frac{1}{y_{\mathrm{d}}}\left(\frac{Q_{\mathrm{d}}}{N}\right)^{\eta}<0, \\
& \Delta_{12}=\frac{\partial T_{\mathrm{d}}^{*}\left(y_{\mathrm{d}}, Q_{\mathrm{d}}\right)}{\partial Q_{\mathrm{d}}}=\left(1-\frac{1}{\beta_{1 \mathrm{~d}}}\right) \frac{y_{\mathrm{d}}(\eta-b+a)}{N\left(\rho-\alpha_{2}\right) Q_{\mathrm{d}}}\left(M_{\mathrm{d}}-\frac{\eta \gamma}{(\eta-b+a)}\right)>0 .
\end{aligned}
$$

Totally differentiating Eq. (25) with respect to $y_{\mathrm{d}}$, and using Eqs. (26)-(28) yields

$$
\frac{\partial Q_{\mathrm{d}}}{\partial y_{\mathrm{d}}}=\frac{\Delta_{21}}{-\Delta_{22}}>0
$$

where

$$
\begin{aligned}
& \Delta_{22}=\frac{\partial D_{\mathrm{d}}^{*}\left(y_{\mathrm{d}}, Q_{\mathrm{d}}\right)}{\partial Q_{\mathrm{d}}}=-\eta(\eta-b+a) N^{1-\eta} Q_{\mathrm{d}}^{\eta-2}<0,{ }^{18} \\
& \Delta_{21}=\frac{\partial D_{\mathrm{d}}^{*}\left(y_{\mathrm{d}}, Q_{\mathrm{d}}\right)}{\partial y_{\mathrm{d}}}=\frac{(N-1+b-a)}{N\left(\rho-\alpha_{2}\right)} Q_{\mathrm{d}}^{b-a-1}>0 .
\end{aligned}
$$

The Jacobian condition also requires that

$$
\Delta_{11} \Delta_{22}-\Delta_{12} \Delta_{21}>0
$$

We depict the impact of $Q_{\mathrm{d}}$ on $y_{\mathrm{d}}$ in Eq. (A1), and that of $y_{\mathrm{d}}$ on $Q_{\mathrm{d}}$ in Eq. (A4) by line $T_{\mathrm{d}} T_{\mathrm{d}}$ and line $D_{\mathrm{d}} D_{\mathrm{d}}$ in Fig. 1, respectively. Eq. (A7) requires that the slope of $D_{\mathrm{d}} D_{\mathrm{d}}$ be steeper than that of $T_{\mathrm{d}} T_{\mathrm{d}}$, and we find that this requirement is satisfied.

\section{Appendix B. Relationship between $y_{\mathrm{c}}$ and $Q_{\mathrm{c}}$}

Totally differentiating Eq. (29) with respect to $Q_{\mathrm{c}}$ and using Eqs. (31)-(33) yields

$$
\frac{\partial y_{\mathrm{c}}}{\partial Q_{\mathrm{c}}}=\frac{\Delta_{12}^{\prime}}{-\Delta_{11}^{\prime}}>0
$$

where

$$
\begin{aligned}
& \Delta_{11}^{\prime}=\frac{\partial T_{\mathrm{c}}^{*}\left(y_{\mathrm{c}}, Q_{\mathrm{c}}\right)}{\partial y_{\mathrm{c}}}=-\frac{N}{y_{\mathrm{c}}}\left(\frac{Q_{\mathrm{c}}}{N}\right)^{\eta}<0, \\
& \Delta_{12}^{\prime}=\frac{\partial T_{\mathrm{c}}^{*}\left(y_{\mathrm{c}}, Q_{\mathrm{c}}\right)}{\partial Q_{\mathrm{c}}}=\left(1-\frac{1}{\beta_{1}}\right) \frac{y_{\mathrm{c}}(\eta-b+a)}{\left(\rho-\alpha_{2}\right)(b-a) Q_{\mathrm{c}}}\left(M_{\mathrm{c}}-\frac{\eta \gamma}{(\eta-b+a)}\right)>0 .
\end{aligned}
$$

Totally differentiating Eq. (30) with respect to $y_{\mathrm{c}}$, and using Eqs. (31)-(33) yields

$$
\frac{\partial Q_{\mathrm{c}}}{\partial y_{\mathrm{c}}}=\frac{\Delta_{21}^{\prime}}{-\Delta_{22}^{\prime}}>0
$$

where

$$
\begin{aligned}
& \Delta_{22}^{\prime}=\frac{\partial D_{\mathrm{c}}^{*}\left(y_{\mathrm{c}}, Q_{\mathrm{c}}\right)}{\partial Q_{\mathrm{c}}}=-\eta(\eta-b+a) N^{1-\eta} Q_{\mathrm{c}}^{\eta-2}<0, \\
& \Delta_{21}^{\prime}=\frac{\partial D_{\mathrm{c}}^{*}\left(y_{\mathrm{c}}, Q_{\mathrm{c}}\right)}{\partial y_{\mathrm{c}}}=\frac{1}{\left(\rho-\alpha_{2}\right)} Q_{\mathrm{c}}^{b-a-1}>0 .
\end{aligned}
$$

\footnotetext{
$\overline{18}$ We assume that $\eta-\mathrm{b}+\mathrm{a}>0$ to ensure that this second-order condition holds.
} 
The Jacobian condition also requires that

$$
\Delta_{11}^{\prime} \Delta_{22}^{\prime}-\Delta_{12}^{\prime} \Delta_{21}^{\prime}>0
$$

We depict the impact of $Q_{\mathrm{c}}$ on $y_{\mathrm{c}}$ in Eq. (B1), and that of $y_{\mathrm{c}}$ on $Q_{\mathrm{c}}$ in Eq. (B4) by line $T_{\mathrm{c}} T_{\mathrm{c}}$ and line $D_{\mathrm{c}} D_{\mathrm{c}}$ in Fig. 1, respectively. Eq. (B7) requires that the slope of line $D_{\mathrm{c}} D_{\mathrm{c}}$ be steeper than that of line $T_{\mathrm{c}} T_{\mathrm{c}}$ in Fig. 1, and we find that this condition is satisfied.

\section{Appendix C. Proof of Proposition 3}

Partially differentiating $T_{\mathrm{c}}^{*}(\cdot)$ in Eq. (29) with respect to $\sigma, \alpha_{1}$, and $\gamma$ yields

$$
\begin{aligned}
& \frac{\partial T_{\mathrm{c}}^{*}(\cdot)}{\partial \sigma}=\frac{-1}{\beta_{1}^{2}} \frac{\partial \beta_{1}}{\partial \sigma} \frac{y_{\mathrm{c}}}{N\left(\rho-\alpha_{2}\right)}\left[Q_{\mathrm{c}}^{b-a}-\gamma\right]>0, \\
& \frac{\partial T_{\mathrm{c}}^{*}(\cdot)}{\partial \alpha_{1}}=\frac{-1}{\beta_{1}^{2}} \frac{\partial \beta_{1}}{\partial \alpha_{1}} \frac{y_{\mathrm{c}}}{\left(\rho-\alpha_{2}\right)(b-a)}\left[Q_{\mathrm{c}}^{b-a}-\gamma\right]<0, \\
& \frac{\partial T_{\mathrm{c}}^{*}(\cdot)}{\partial \gamma}=\left(1-\frac{1}{\beta_{1}}\right) \frac{y_{\mathrm{c}}}{\left(\rho-\alpha_{2}\right)(b-a)}>0,
\end{aligned}
$$

where $\partial \beta_{1} / \partial \sigma<0$, and $\partial \beta_{1} / \partial \alpha_{1}>0$. Partially differentiating $D_{\mathrm{c}}^{*}(\cdot)$ in Eq. (30) with respect to $\sigma, \alpha_{1}$, and $\gamma$ yields

$$
\frac{\partial D_{\mathrm{c}}^{*}(\cdot)}{\partial h}=0
$$

where $h=\sigma, \alpha_{1}$, or $\gamma$.

Furthermore, the impacts of $\sigma, \alpha_{1}$, and $\gamma$ on $T_{\mathrm{d}}^{*}(\cdot)$ and $D_{\mathrm{d}}^{*}(\cdot)$ are qualitatively the same as those on $T_{\mathrm{c}}^{*}(\cdot)$ and $D_{\mathrm{c}}^{*}(\cdot)$, respectively.

\section{References}

Anderson, J.E., 1993. Land development, externalities, and pigouvian taxes. Journal of Urban Economics 33 (1), $1-9$.

Bar-Ilan, A., Strange, W.C., 1996. Investment lags. American Economic Review 86, 610-622.

Capozza, D., Li, Y., 1994. The intensity and timing of investment: the case of land. American Economic Review 84, 889-904.

Childs, P.D., Riddiough, T.J., Triantis, A.J., 1996. Mixed uses and the redevelopment option. Real Estate Economics 24 (3), 317-339.

Cunningham, C.R., 2004. Growth Controls, Real Options, and Land Development. Mimeo. Department of Economics, Syracuse University..

Dixit, A.K., Pindyck, R.S., 1994. Investment under Uncertainty. Princeton University Press, Princeton, NJ.

Fischel, W., 1985. The Economics of Zoning Laws. Johns Hopkins University Press, Baltimore.

Grenadier, S.R., 1996. The strategic exercise of options: development cascades and overbuilding in real estate. Journal of Finance 51 (5), 1653-1679.

Grenadier, S.R., 2000. Equilibrium with time-to-build: a real options approach. In: Brennan, M., Trigeorgis, L. (Eds.), Project Flexibility, Agency and Competition. Oxford University Press, Oxford, pp. 275-298.

Jou, J.-B., 2001. Environment, asset characteristics, and optimal effluent fees. Environmental and Resource Economics 20, 27-39.

Jou, J.-B., 2004. Environment, irreversibility and optimal effluent standards. Australian Journal of Agricultural and Resource Economics 48 (1), 127-158.

Jou, J.-B., Lee, T., 2007. Do tighter restrictions on density retard development?. Journal of Real Estate Finance and Economics 34 (2), 225-232.

Laffont, J.-J., 1988. Fundamentals of Public Economics. The MIT Press, Cambridge. 
McFarlane, A., 1999. Taxes, fees, and urban development. Journal of Urban Economics 46 (3), 416-436.

Pivo, G., 1992. Local Government Planning Tools. Growth Management Planning and Research Clearinghouse, Department of Urban Planning and Design. University of Washington, Seattle.

Quigg, L., 1993. Empirical testing of real option-pricing cost. Journal of Financial Economics 48, 621-639.

Riddiough, T.J., 1997. The economic consequences of regulatory taking risk on land value and development activity. Journal of Urban Economics 41 (1), 56-77.

Titman, S., 1985. Urban land prices under uncertainty. American Economic Review 75, 505-514.

Tresch, R.W., 2002. Public Finance: A Normative Theory. Academic Press, San Diego.

Turnbull, G.K., 1988. Residential development in an open city. Regional Science and Urban Economics 18 (2), $307-320$.

Turnbull, G.K., 1991. A comparative dynamic analysis of zoning in a growing city. Journal of Urban Economics $29,235-248$.

Turnbull, G.K., 2002. Land development under the threat of taking. Southern Economic Journal 69 (2), 468-501.

Turnbull, G.K., 2005. The investment incentive effects of land use regulations. Journal of Real Estate Finance and Economics 31 (4), 357-395.

Williams, J.T., 1991. Real estate development as an option. Journal of Real Estate Finance and Economics 4, 191-208.

Williams, J.T., 1997. Redevelopment of real assets. Real Estate Economics 25 (3), 387-407. 